\title{
DON JULIÁN Y SON EXCELLENCE, DE JAUME SABARTÉS: DOS APORTACIONES A LA NOVELA DEL DICTADOR POR EL SECRETARIO DE PICASSO
}

\author{
POR \\ Margarida CASACUBERTA \\ Universitat de Girona
}

Jaume Sabartés, "poeta Decadente"

El nombre de Jaume Sabartés (Barcelona 1881-París 1968) es probablemente conocido en todo el mundo, pero nadie sabe todavía quién fue realmente el secretario y amigo de Pablo Picasso. A Sabartés pertenecen los primeros estudios críticos sobre la obra del artista y suyos son, en buena parte, los materiales biográficos sobre los cuales se empezó a construir el mito de Picasso (Léal 284-285).

En la base de todo gran mito existe una narración. El Dr. Johnson tuvo a Boswell, Goethe contó con la pluma de Eckermann además de la suya, Dalí se reescribió a sí mismo una y otra vez, y Picasso acudió a su amigo barcelonés, el modelo de su Poeta decadente (1901), artista sin obra conocida, escritor frustrado, para que le explicara -a él y a su obra- ante el mundo. Y no andaba equivocado Picasso cuando, en 1935, el peor año de su vida (Léal 286-287), coincidiendo con la ruptura de su matrimonio con la bailarina Olga Khokhlova y después de treinta años de separación del amigo, propuso a Jaume Sabartés trasladarse a París para vivir junto a él ${ }^{1} \mathrm{y}$ hacer las veces de secretario, hombre de confianza y, sobre todo, de biógrafo. Porque Sabartés fue ante todo un escritor. Lo demuestra una de sus primeras aproximaciones a la vida y obra de Picasso, escrita en español en 1941y publicada en francés, Picasso: Portraits et Souvenirs (1946), seguida de Picasso. Documents iconographiques (1954), y sobre todo sus tres novelas Don Julián, Son Excellence y Tú qué sabes, escritas en español

\footnotetext{
Esta es la versión de los hechos que Sabartés expone en su conocida biografía de Picasso: Portraits et Souvenirs. París: Louis Carré \& Maximilien Vox, 1946. Sin embargo, la primera carta que Sabartés envía a su amigo José Mora Guarnido poco después de abandonar Montevideo está fechada París en 15 de diciembre de 1932. Esta interesante correspondencia, compuesta de un total de 11 cartas, está depositada en la Université de Lille 3: Archivo José Mora Guarnido-Montevideo, Herederos de Alcides Giraldi-Lille, Université Lille-Nord de France. Agradezco a Norah Giraldi Dei Cas y a Fatiha Idmhand la posibilidad de consultar la Correspondencia Sabartés-José Mora Guarnido.
} 
durante los años de la ocupación alemana de París y publicadas, las dos primeras, en francés en 1947 y 1949 respectivamente. ${ }^{2}$

Este artículo se propone construir un primer relato de la vida y la obra del escritor Jaume Sabartés desde el epicentro de su obra narrativa, situado "nel mezzo del camin" de una biografía intelectual que se inicia en la Barcelona modernista, se traslada en 1904 a la Guatemala de Manuel Estrada Cabrera y se exilia en Montevideo antes de su regreso a Europa como secretario de Pablo Picasso pocos meses antes del estallido de la Guerra Civil Española. El "poeta decadente" y representante de la "bohemia negra" que debutó en catalán en las páginas de la revista Joventut (1900-1906) con el pseudónimo "Jacobus Sabartés" firmará como Jaime Sabartés tanto los artículos periodísticos publicados en la prensa guatemalteca y uruguaya (Luján, Carlos Mérida 205; Basso 14-18) como la prosa ensayística y narrativa que escribe arropado por Picasso a partir de 1936 hasta cerca del final de su vida, en 1968.

Fue a Sabartés a quien Picasso confió la construcción literaria de su imagen de artista y a quien utilizó para que esta construcción perdurara, más allá de la muerte de ambos, en el Museo Picasso de Barcelona, inaugurado en 1963 con el nombre de Colección Sabartés y al que Picasso legó el conjunto de su obra anterior a su definitivo traslado a París en 1904, convirtiéndose a lo largo de cincuenta años en el principal depositario y curator de los inicios de la trayectoria del artista, estrechamente ligada-por voluntad del propio Picasso- a la aventura intelectual y vital de Jaume Sabartés. Nos encontramos ante una existencia marcada por los avatares del siglo xx (poscolonialismo, emigraciones, fascismos, guerras, exilios), una identidad escindida que se expresa a través de la escritura y de distintas lenguas (del catalán de sus primeros escritos al español de sus ensayos y novelas de madurez), una trayectoria intelectual que merece ser rescatada del olvido dorado al que le condena el ser universalmente considerado como "la sombra de Picasso" (Léal 287).

\section{“ESCRIBE, HOMBRE, ESCRIBE... Y TE PONDRÁS MEJOR”}

Jaume Sabartés se reúne con Picasso el 12 de noviembre de 1935 para convertirse en su secretario personal. ${ }^{3} \mathrm{Al}$ cabo de pocos meses escribe una primera biografía del

2 Jaime Sabartés, "Don Julián (roman)" [Traducido del español por Françoise Bonifas], Europe, 25:18 (1947: juin) 56-81; 25:19 (1947: juil.) 55-84; 25:20 (1947: août) 64-102; $25: 21$ (1947: sept.) 81-108; 25:22 (1947: oct.) 68-98; 25:23 (1947: nov.) 78-87, y 25:24 (1947: déc.) 69-89. Apareció en volumen en Sabartés, Jaime. Don Julián, Paris: Les Éditeurs Réunis, 1947; Son Excellence [Traducido del español por Geneviève Laporte]. París: Les Éditeurs Réunis, 1949. Y tú qué sabes es el título del manuscrito mecanografiado que se conserva en el "Fons Sabartés" del Museu Picasso de Barcelona y que seguramente corresponde a la novela de próxima aparición anunciada en la cubierta de Son Excellence con el título Tu ne sais pas y que probablemente nunca llegó a ver la luz.

3 Tras recibir una carta, el día 13 de julio del mismo año 1935, que Sabartés rememora en su libro Picasso. Documents iconographiques [Traducción de Félia Léal et Alfred Rosset], 68.

Revista Iberoamericana, Vol. LXXXI, Núm. 250, Enero-Marzo 2015, 31-52 
artista, Picasso en su obra, ${ }^{4}$ y publica un texto sobre "La literatura de Picasso" en la revista Cahiers d'Art dedicada a Picasso 1930-1935 con motivo de la exposición que se va a ver en Barcelona, Bilbao y Madrid en el primer trimestre de 1936. ${ }^{5}$ Después del golpe de estado militar del 18 de julio de 1936, Sabartés comparte con Picasso su compromiso con la legalidad republicana durante la Guerra Civil Española y el horror ante las primeras masacres causadas en la población civil por la aviación alemana e italiana, aliadas del bando golpista. Ambos amigos vivirán juntos el posterior estallido de la Segunda Guerra Mundial y la ocupación alemana de París. Es precisamente en este momento cuando Sabartés decide ocupar su tiempo trabajando en lo que él sabe: escribir. Así lo explica Sabartés en el relato Picasso: Portraits et souvenirs (1946), el primer resultado tangible de esta decisión:

Un día, mientras estoy cavilando acerca de lo que podría hacer para ocupar mi tiempo, Picasso, que observa en mí signos de impaciencia y se da cuenta de que la inacción me va agriando el humor, dejándose llevar por el suyo, que siempre se inclina a resolver todo problema, por grave que sea, entregándose a la cura del trabajo, me incita a que yo haga lo mismo.

-¿Pero en qué? -le digo-, ¿cómo?¿Cómo puedo trabajar en este tiempo?...

-Escribe, hombre; escribe... Escribe no importa qué -me dice-. Escribe para ti, si quieres; aunque sólo sea para ti; pero escribe, y ya verás como toda la murria se te irá y te pondrás mejor. ${ }^{6}$

Parece ser que se encontraban en Royan ${ }^{7}$ cuando Picasso aconsejó a Sabartés que escribiera "no importa qué". Y Sabartés escribió la primera biografía de Picasso sobre el hilo argumental de la amistad que los dos compartían desde finales de siglo en Barcelona. Lo hizo sobre una trama construida con los retratos y los recuerdos del propio narrador, que se convierte, con ello, en parte integrante de la vida y de la creación artística del que pronto va a ser considerado el artista por antonomasia del siglo xx. Tal como Sabartés puntualiza en el breve párrafo que, a modo de presentación, añade a la publicación del libro en español, Picasso. Retratos y recuerdos "es un relato, y nada más, de cosas que he vivido con Picasso, siguiendo el curso de los recuerdos. El asunto es interesante y estoy casi convencido de despertar la curiosidad del lector con sólo el título, porque el

4 Sabartés, Jaime. Picasso en su obra. Madrid: Cruz y Raya, 1936.

5 Sabartés, J. "La literatura de Picasso", Picasso 1930-1935. París: Éditions Cahiers d'Art, 4-I-1936, 89102.

6 Sabartés, Jaime. Picasso. Retratos y recuerdos. Madrid: Afrodisio Aguado, 1953, p. 5. Sabartés escribió el original del libro en castellano y fue traducido al francés por los historiadores del arte Paule-Marie Grand y André Chastel.

7 Sobre la estancia en Royan de Picasso desde agosto de 1939 hasta septiembre de 1940, véase Dufaud, Gérard. Picasso, un réfugié à Royan, 1939-1940. La Rochelle: Comédiart, 2012.

Revista Iberoamericana, Vol. LXXXI, Núm. 250, Enero-Marzo 2015, $31-52$ ISSN 0034-9631 (Impreso) ISSN 2154-4794 (Electrónico) 
nombre de Picasso es suficientemente sugestivo." (Sabartés, Retratos 5) Los retratos que establecen el hilo conductor de dos vidas que se encuentran en 1898 en Barcelona, que se separan a partir de 1904, cuando Picasso se instala definitivamente en París y Sabartés emigra a Guatemala, y que se reencuentran de nuevo en París en 1935, son los del modelo Jaume Sabartés, el objeto creado e inmortalizado por la mirada y la obra picassiana y al mismo tiempo el sujeto de donde procede el material sensible -los recuerdos, la memoria voluntaria e involuntaria, el consciente y el inconsciente-a partir del cual la literatura construye la vida y la convierte en la única realidad perdurable.

Híbrido, por lo tanto, entre biografía y autobiografía, Picasso. Retratos y recuerdos es la obra que justificaría por sí sola la condición de escritor de Jaume Sabartés por encima de cualquier otra definición posible de la "desdibujada" figura del secretario de Picasso. ${ }^{8}$ En este sentido, y aunque sea de forma inconsciente, la biografía de Picasso fue la estrategia que Sabartés utilizó para fijar, junto con su estereotipada imagen de "sombra" del gran Artista, su propia y ya incuestionable identidad de escritor. Afirma Sabartés que "poeta" era uno de los mayores elogios que Picasso era capaz de dedicar a los demás. Y como "poeta" se auto-representa Sabartés no sólo a partir de las páginas que dedica a su retrato como Poeta decadente, sino por la escritura misma del libro a instancias de su amigo, como acabamos de ver.

Sabartés escribe Picasso. Retratos y recuerdos en un lugar y en una circunstancia histórica que explican la sensación de melancolía, abatimiento -la "murria"- que imprime el tono general del libro. Escrito en Royan durante los meses en que Picasso se instala en la villa veraniega de la costa atlántica francesa tras el estallido de la Segunda Guerra Mundial y durante los primeros meses de la ocupación alemana de París, el relato empieza en el preciso instante del encuentro entre los adolescentes Picasso y Sabartés en la Barcelona de fin de siglo y se detiene el 23 de agosto de 1940, cuando Picasso decide dejar Royan y volver a la capital ocupada. ${ }^{9}$ El manuscrito está fechado en París, 22 de septiembre de 1941, pero el abatimiento debió continuar después de esta primera obra, porque Sabartés emprendió durante los años siguientes la escritura de tres novelas, dos de las cuales abordan precisamente los años que quedan elididos en Picasso. Retratos y recuerdos, sus años guatemaltecos, entre 1904 y 1927.

De hecho, se conocen muy pocos detalles sobre la vida guatemalteca de Jaume Sabartés. Como tantos otros jóvenes españoles, después del desenlace de la guerra de Cuba (1898) y de la crisis económica y política en que se vio sumido el Estado español a lo largo del siglo xIX -radicalizada tras la pérdida de las colonias de Ultramar-y

8 Véase Sesé, Teresa. "Sabartés, el amigo desdibujado de Picasso". La Vanguardia (3-I-2011). Una primera aproximación a la lectura de la (auto)biografía de Picasso por Sabartés en Casacuberta, Margarida. “Jaume Sabartés, retrats i records". L'Avenç [Barcelona], 388 (marzo 2013) 36-43.

9 Uno de los últimos ensayos sobre París bajo la ocupación alemana, Riding, Alan. Y siguió la fiesta: la vida cultural en el París ocupado por los nazis. Barcelona: Galaxia Gutenberg, 2011. 
coincidiendo con la decisión de Picasso de instalarse definitivamente en París, Sabartés emprendió el viaje a Guatemala. Sus impresiones de viaje y el primer contacto con el país se convierten en el tema del último artículo que envió “Jacobus Sabartés” a la revista modernista Joventut en diciembre de 1904. ${ }^{10}$ A partir de entonces no se conocen escritos autobiográficos que den testimonio de los veinticinco años en que Sabartés vivió entre Ciudad de Guatemala y Quezaltenango, aunque sí que aparecen, convenientemente ficcionalizados, como veremos, en sus novelas.

Hasta 1981, cuando se publica la biografía que dedicó a Sabartés el escritor Luis Luján Muñoz, Jaime Sabartés en Guatemala: 1904-27, poco había trascendido de la actividad intelectual del catalán en Centroamérica. En 1966, el propio Luján empezaba su artículo "Jaime Sabartés: intelectual español en Guatemala" partiendo de la base de que pocos guatemaltecos sabían que "el actual secretario, imprescindible colaborador e íntimo amigo del gran artista español Pablo Picasso vivió durante largos años en Guatemala", y añadía que "incluso quienes lo conocieron en Guatemala han perdido contacto con él desde su partida a Europa" (Luján 25). A parte de cuestiones biográficas aún muy vagas que sin embargo lograría esclarecer en la biografía posterior, Luján presenta a Sabartés como "un intelectual español que se vinculara con los movimientos artístico y literario de la Guatemala del primer cuarto de este siglo y, además, como autor de dos novelas, asimismo casi desconocidas en nuestro medio, que se refieren, sin mencionar nombres, a la Guatemala de la dictadura de Manuel Estrada Cabrera. Son tales obras Don Julián y Son Excellence” (Luján 27). Luján presenta a Sabartés como un cosmopolita que conocía "París, Nueva York, Barcelona y Madrid" antes de llegar a la capital de Guatemala y de vincularse al grupo de jóvenes intelectuales de la ciudad de Xelajú, "Los Líricos", entre los que destaca a Rafael Yela Günther, Carlos Mérida, Humberto Garavito, Alberto Velázquez, Alberto Aguilar Chacón, Osmundo Arriola, José Valverde y Emiro Fuensanta. También destaca el vínculo de Sabartés con el escritor Rafael Arévalo Martínez, director de la revista Juan Chapín (1913-1914) y autor, entre otras, de las novelas El hombre que tenía cara de caballo (1914) y Manuel Aldano (1922), y de la biografía de Manuel Estrada Cabrera Ecce Pericles (1939). Sabartés dedica a Rafael Arévalo un guiño en Don Julián al convertirlo en uno de los personajes corales de la novela, Don Rafa, correspondiendo con ello al retrato de Sabartés "avec des coloris guatémaliens" que, según Jaime Díaz-Rozzotto, Rafael Arévalo incluye en su Manuel Aldano (Díaz-Rozzotto 40). Es el mismo Díaz-Rozzotto quien, en un artículo de conjunto sobre la literatura guatemalteca publicado en la revista Europe en 1968, al tratar de la "Generación de 1910" y de la importancia que tuvieron sobre sus jóvenes representantes el poeta Porfirio Barba-Jacob y Jaume Sabartés, afirma: "Il

10 Sabartés, Jacobus. “De casa a ca’l oncle”. Joventut [Barcelona] 260 (2-II-1905): 75-77. El artículo está firmado en Guatemala en diciembre de 1904.

Revista Iberoamericana, Vol. LXXXI, Núm. 250, Enero-Marzo 2015, 31-52 ISSN 0034-9631 (Impreso)

ISSN 2154-4794 (Electrónico) 
faudra, un jour, rassembler ce que doit l'art guatémaltèque à ces deux étranges figures" (Díaz-Rozzotto 40).

Por lo que respecta a la "extraña" figura de Sabartés, Luján pone el acento en sus dos novelas, Don Julián y Son Excellence, ya que, como señala el biógrafo guatemalteco,

\begin{abstract}
Curiosamente no existe edición española de las mismas; fueron, empero, escritas en español, traducidas al francés y publicadas en París, Desde luego no hay una sola alusión a Guatemala ni a hombres de Guatemala, pero basta para alguien nacido en ella con leerlas, para darse cuenta de que aquella ciudad allí descrita y aquel ambiente no pueden ser sino las de la Guatemala de la dictadura cabrerista. El propio título de la segunda de estas novelas, Son Excellence, no es sino una alusión al presidente Estrada Cabrera, de una manera por cierto un poco similar a la extraordinaria novela de Miguel Ángel Asturias El Señor Presidente, publicada en 1946. El nombre con que inicialmente pensó Sabartés llamar a esta obra fue Il a bien mérité de la patrie, expresión acuñada por el servilismo de la época para aludir al presidente Estrada Cabrera, personaje que también mereciera el ser tratado por otros autores, tales como Arévalo Martínez en Ecce Pericles y Carlos Wyld Ospina en El Autócrata. De manera que a los libros ya conocidos sobre la dictadura cabrerista debemos añadir estos dos, muy importantes, de Jaime Sabartés (Luján 27).
\end{abstract}

Don JULIÁN y SON EXCELLENCE: DOS NUEVAS APORTACIONES A LA NOVELA DEL DICTADOR

Don Julián y Son Excellence pertenecen a la categoría de la "novela del dictador", término que la historiografía literaria ha fijado para designar una consistente tradición de novela hispanoamericana protagonizada por la figura del jefe de estado que detenta un poder absoluto y lo ejerce de forma despótica y tiránica haciendo uso de la violencia en todos los órdenes de la existencia de los ciudadanos a los que gobierna. ${ }^{11}$ Juan Carlos García describe la novela del dictador como una "hispanoamericanización" del tópico literario del tirano "configurando un dictador que concentra todo el poder de una nación ubicada en una Hispanoamérica real o ficticia. Este dictador gobierna un pueblo que se compone de personas que hablan o español o alguna lengua indígena del territorio (o ambas). El mundo narrado se corresponde, en muchos sentidos, con el mundo real: relaciones político-sociales, geografía, alusiones históricas, personajes, costumbres, niveles de lenguaje, formas lingüísticas regionales y nacionales, etc. El gobierno que representa el dictador es, naturalmente, universal y generalmente sostenido por medio de la fuerza. El resultado del uso de esta fuerza es la persecución generalizada a los opositores, el encarcelamiento de muchos, la tortura y el asesinato" (García 12).

${ }^{11}$ Sobre la novela del dictador, véase, entre otros, los estudios de Zuluaga; Calviño Iglesias; Mejía Ruiz; Pacheco; Bellini, y las tesis en línea de García; Gallego Cuiñas; Florez Espinoza, especialmente interesante por la focalización de la víctima como personaje literario.

Revista Iberoamericana, Vol. LXXXI, Núm. 250, Enero-Marzo 2015, 31-52 ISSN 0034-9631 (Impreso)

ISSN 2154-4794 (Electrónico) 
Personaje que "ordena y crea" la realidad histórica de la América postcolonial, el dictador de la literatura hispanoamericana en general y de la novela en particular, "independientemente de que constituya un personaje principal o secundario y que se encuentre en obras en las cuales predomine un dictador, un caudillo o una dictadura, se caracteriza por ser una autoridad real dentro de la narración. Su mandato abarca el campo y la ciudad y se ejerce sobre personas, animales y objetos. Las órdenes que emanan de esta autoridad no se desobedecen y tienen la facultad de crear situaciones nuevas, lo que lo aproxima a ser entidad todopoderosa o Dios" (García 7 y 13). Aunque esta figura recorre la tradición literaria hispanoamericana en su conjunto, la novela del dictador nace, al mismo tiempo que la novela moderna, con la solidificación de la independencia de las colonias y la formación de las repúblicas, y se enriquece con las aportaciones del romanticismo, del costumbrismo y del realismo, adquiriendo su principal significación con el modernismo. No en vano uno de los primeros y más emblemáticos ejemplos de la novela del dictador se debe al modernista Ramón del Valle-Inclán (Rodríguez 41-50; Subercaseaux 45-62 ), autor de Tirano Banderas (1926), entendiendo el modernismo como un movimiento intelectual de alcance europeo y americano que persigue la modernización de una sociedades consideradas caducas y provincianas por unos jóvenes (y no tan jóvenes) intelectuales que, en nombre de la juventud, pretenden "regenerarlas" - es decir, modernizarlas, (re)nacionalizarlas y internacionalizarlas- a través de la educación y de la cultura.

La América postcolonial y la España postcolonialista generaron en el largo cambio del siglo XIX al Xx importantes movimientos intelectuales caracterizados por la profunda (auto)crítica en relación con el funcionamiento de sus respectivas sociedades que comparten la ciudad de París como faro de la modernidad a la que todos ellos aspiran (Colombi Viaje). Es el caso de Jaume Sabartés, procedente del movimiento intelectual que se forja en Barcelona en torno a la revista L'Avenç (1889-1893) durante la última década del siglo XIX con el nombre de "modernisme" y que Joan-Lluís Marfany define como el proceso de transformación de la cultura catalana, considerada por los mismos intelectuales modernistas como caduca, tradicionalista y regional, en una cultura moderna, europea y nacional (Marfany 34).

Jaume Sabartés dedica unas cuantas páginas de su ensayo Picasso. Documents iconographiques a definir el movimiento que, según él, determinó la evolución de la trayectoria artística de Picasso para desmentir uno de los tópicos que la incipiente bibliografía sobre el artista va repitiendo y que el propio artista parece querer controlar a través de su amigo y biógrafo de confianza:

Madrid a très peu marqué dans le développement de son esprit, mais Barcelone, en revanche, exerça sur lui une influence beaucoup plus forte. Pablo avait à peine quinze ans quand il arriva à Barcelone, et l'ambiance de cette ville, à la fin du siècle dernier était inquiète et agitée, sous le signe du sentimentalisme éminemment régionaliste qui

Revista Iberoamericana, Vol. LXXXI, Núm. 250, Enero-Marzo 2015, 31-52 ISSN 0034-9631 (Impreso)

ISSN 2154-4794 (Electrónico) 
entourait la renaissance de la langue catalane. Il y avait là un mouvement idéaliste propre à séduire toute âme généreuse. Et Pablo Ruiz se sentit tout de suite comme chez lui dans cette grande ville.

Pour le docteur don Salvador Ruiz Blasco, Madrid était le seul endroit où un artiste espagnol pût conquérir la gloire et la fortune; mais Pablo préférait de beaucoup le mouvement et l'agitation intellectuelle qu'il venait de découvrir en Catalogne, car la jeunesse qui l'accueillit immédiatement, sans hésiter, aspirait à autre chose: elle portait ses vues au-delà de la frontière des Pyrénées et il fut amené à penser sérieusement à Paris, terre promise des arts et de la liberté.

[Madrid tenía poco en cuanto al desarrollo del espíritu, pero Barcelona, por el contrario, tenía en él una influencia mucho más fuerte. Pablo tenía apenas quince años cuando vino a Barcelona, y el ambiente de esta ciudad a finales del siglo pasado se daba bajo el signo de un sentimentalismo eminentemente regionalista que rodeaba el renacimiento del idioma catalán. Hubo un movimiento idealista para seducir a cualquier alma generosa. Pablo Ruiz se sentía como en casa en esta ciudad.

Para el Dr. Don Salvador Ruiz Blasco, Madrid era el único lugar donde un artista español podría ganar fama y fortuna; Pablo prefería al movimiento y a la agitación intelectual que acababa de descubrir en Cataluña para la juventud que la saludaba en seguida, sin dudarlo aspiraba a algo más: ella llevaba sus puntos de vista más allá de la frontera de los Pirineos, fue llevado a pensar seriamente en París, la tierra prometida de las artes y de la libertad] (Sabartés, Documents 41-42; traducción mía). ${ }^{12}$

El mismo Sabartés fue uno de los jóvenes intelectuales modernistas que acogió a Pablo Ruíz Picasso y lo introdujo en el movimiento liderado por el artista y escritor Santiago Rusiñol que durante los años de la guerra de Cuba (1895-1898) se posicionó a favor de las colonias insurrectas y se opuso a la guerra al mismo tiempo que emprendía una importante crítica a la tendencia del Estado español a "vivir del pasado" y de espaldas a la modernidad europea. También Sabartés emprendió el viaje a París que los jóvenes modernistas anhelaban, pero sólo durante unos pocos meses. A finales de 1904, al mismo tiempo que Picasso emprendía su último y definitivo viaje dispuesto a "devorar París" (McCully 2011), Sabartés tomaba el camino de las Américas.

En Guatemala, donde años antes había emigrado un tío materno suyo, Francisco Gual Oromí, comerciante, Jaume Sabartés ejerció como divulgador de las ideas y de la actitud modernista, lo que le ha reportado la fama de revulsivo de la cultura guatemalteca durante el primer cuarto del siglo xx. Cuando regresó a Europa, a finales de la década de los veinte por motivos al parecer personales, encontró a España sumida en la dictadura del general Primo de Rivera (1923-1930) y regresó a América, concretamente a Montevideo,

12 Sabartés dedica al movimiento modernista las páginas 41-48 de un ensayo de poco más de setenta páginas. Recordemos que el grueso del libro está formado por la reproducción de los documentos sobre los cuales Sabartés esclarece los tópicos más manidos sobre la imagen del artista.

Revista Iberoamericana, Vol. LXXXI, Núm. 250, Enero-Marzo 2015, $31-52$ 
donde vivió, como hemos visto, hasta final de 1932. De nuevo en París, esta vez para quedarse, la reacción de Sabartés ante el fascismo que en los años treinta se extendía por Europa y que asoló a partir de 1936 a su país natal y a partir de 1939 a Francia, fue escribir su propia experiencia sobre la tiranía que él conocía de forma directa, ya que había vivido durante casi veinte años bajo la dictadura de Manuel Estrada Cabrera en Guatemala (1898-1920) y había coincidido, durante su estancia en Montevideo, con los preparativos de otra dictadura, la de José Luis Gabriel Terra (1933-1938).

Y sin embargo, Sabartés nunca escribió sus memorias. Eligió la novela y, por lo tanto, un género de ficción, el más proteico, como vehículo para combatir el abatimiento y, sobre todo -aunque él quizá no lo hubiera admitido debido a su papel de eterno secundario-, para posicionarse contra el fascismo en particular y la tiranía en general en unos momentos de "opresión terrible" en que el escritor, el artista, el intelectual, debe comprometerse (Daix 10-11). ${ }^{13}$ Y, en este contexto, Sabartés asume plenamente su condición de intelectual y escribe su experiencia de la dictadura desde dentro y desde una posición no muy cómoda, como veremos, en tanto que sus dos aportaciones a la novela del dictador abordan, por un lado, los mecanismos de la tiranía -el régimen del terror, la delación y la corrupción- y, por otro, las bases sociales que explican su existencia en un terreno perfectamente abonado donde la frontera entre víctimas y verdugos se diluye de forma inquietante (Dorfman 9-47).

\section{DON JULIÁN O LA NARRACIÓN DE LOS MECANISMOS DEL TERROR POLÍTICO}

La primera de dichas novelas, Don Julián, fue concluida en París el 12 de mayo de 1942, tal como reza la dedicatoria de Sabartés a Picasso en el texto original escrito en español:

A ti, Pablo Ruiz Picasso, y a tu paciencia, dedico y recomiendo este penosísimo trabajo, fiando en que no me has de dejar por mentiroso, si para aliviar mi conciencia de la parte de culpa que me toca, por haberlo consumado, me dejo caer en la debilidad de denunciar la complicidad que te incumbe, apoyado en que me indujiste a perpetrarlo $\mathrm{y}$ en que me incitaste a llevarlo al término en que te lo abandono. ${ }^{14}$

13 Utilizo palabras extraidas de las declaraciones que Picasso hizo al magazine americano New Masses justificando su adhesión al Parti Communiste Français en setiembre de 1944, después de la Libération.

14 Esta nota está pegada en el primer ejemplar de la copia mecanografiada de Don Julián que se conserva en el "Fons Sabartés" del Museu Picasso de Barcelona. El mismo texto aparece reproducido en la primera página del mecanoscrito, una hoja de color violeta claro, firmado por "J Sabartés París 12 de mayo de mil novecientos cuarenta y dos". Agradezco a Silvia Domènech i Margarida Cortadella, responsables, respectivamente, de la Biblioteca y del Centre de Coneixement i Recerca del Museu Picasso, sus constructivos comentarios al artículo producto de su interés personal por la figura y la obra de Jaume Sabartés.

ISevista $\quad$ Iberoamericana,
ISOl. 
Sin embargo Don Julián no apareció publicada hasta 1947 y lo hizo traducida al francés por Françoise Bonifas en las páginas de la revista Europe poco antes de su publicación en La Bibliothèque Française en el mismo año 1947.

Don Julián es una novela construida sobre la historia de la desaparición de un personaje, Don Julián, en el contexto de una sociedad que vive sometida a un régimen de violencia política. El interés de Don Julián recae en el punto de vista desde el cual el narrador aborda y construye un personaje que en ningún momento va aparecer en la narración -salvo a través del recuerdo de los demás personajes- puesto que, tal como el lector intuye desde las primeras páginas de la novela, es una más de las víctimas del régimen dictatorial que en que viven la ciudad y el país innominados en donde se sitúa la acción. Un país cuyos rasgos coinciden con la Guatemala donde Sabartés vivió durante más de veinticinco años -el trazado de las calles que el autor procura respetar en su novela se corresponde con el de Ciudad de Guatemala, la tertulia de escritores que se reúne en el casino es frecuentada por el autor de El hombre que parecía un caballo- aunque la opción del autor de concentrar el universo narrativo en el interior de una casa - un microcosmos- contribuye en gran manera a universalizar el tema de la novela: los mecanismos del terror que sostienen a los regímenes totalitarios del siglo Xx tanto en América como en Europa.

El argumento de Don Julián es en extremo simple: un hombre de poco más de cincuenta años, viudo, con dos hijos, dueño de una tienda de tejidos, que vive con su hermana soltera, Cristina, y una criada, en la casa de la familia que la hermana consigue hacer funcionar como un reloj, un buen día no aparece a la hora del almuerzo como es su costumbre. A partir de este instante y hasta el momento en que aparece el cadáver de Don Julián, cuatro o cinco días más tarde, el narrador omnisciente focaliza, en la primera parte de la novela, el personaje de Cristina, de quien explora el flujo de la conciencia y de la inconsciencia en sus momentos de duermevela, y, en la segunda parte, el personaje externo a la casa, Don Geno, el cuñado de la víctima, que acude desde el pueblo donde vive para socorrer -inútilmente- a la familia. El paso del tiempo, lento aunque inflexible, en el ambiente cerrado de la casa-refugio-prisión que envuelve a los familiares del desaparecido, consigue crear una asfixiante sensación de claustrofobia al mismo tiempo que de paralizante impotencia ante la imposibilidad de los personajes de saber qué está pasando y qué pueden hacer para remediarlo.

Cristina, de cuarenta y cinco años, tótem de la domesticidad, garante del orden del microcosmos que domina, no va a salir de la casa hasta que, al final de la novela, tendrá que reconocer el cadáver del hermano. El mundo exterior, no obstante la aparente tranquilidad que se respira en las calles de la ciudad, esconde la violencia soterrada, latente, de una naturaleza "furiente" (Campillo 37-43) cuya fuerza-siempre desde la mirada expectante y extrañada del emigrante europeo- adquiriere un sentido altamente simbólico en la narrativa de un escritor que procede de una tradición literaria que, hasta

Revista Iberoamericana, Vol. LXXXI, Núm. 250, Enero-Marzo 2015, 31-52 ISSN 0034-9631 (Impreso) 
1905, ha producido en Cataluña novelas como Els sots feréstecs (1901) de Raimon Casellas, El poble gris (1902) de Santiago Rusiñol, La punyalada (1903) de Marian Vayreda y Solitud (1905) de Víctor Català, cuyo principal tema es la exploración del problema de la individualidad planteado simbólicamente a través de la lucha sempiterna y desigual del individuo contra la naturaleza.

Las noticias sobre la desaparición del hermano llegan a la casa a través de los vecinos - de quien Cristina no puede fiarse dado el enrarecido ambiente que se respira en una sociedad dominada por un régimen dictatorial anclado en el miedo, la desconfianza y la corrupción- o del padre Francisco, "entrante" habitual de la casa y representante en la novela de la ambigüedad de la iglesia católica ante los métodos aplicados por la dictadura para asegurar el control social. En este contexto, la segunda parte de la novela empieza con la aparición de un nuevo personaje. Se trata del cuñado del desaparecido, hermano de la mujer difunta y tío de los críos. Enamorado desde siempre de Cristina sin haber conseguido nunca verbalizarlo, Don Geno sigue soltero y vive solo en el campo. Su llegada a la ciudad tras conocer los rumores sobre la suerte de Don Julián permite al narrador focalizar a través de los ojos del personaje que regresa -es decir, la mirada privilegiada de quien pertenece a una comunidad pero puede contemplarla desde fuera por razón de la distancia física y mental- el paisaje humano y urbano que encierra a los habitantes de la casa de Don Julián dentro de un círculo vicioso del cual es imposible escapar y del cual no queda claro que los personajes pretendan escapar, situándose en el estadio de los personajes que, en el marco de la novela modernista anteriormente aludida, permanecen fatalmente supeditados a su "destino", es decir, a una "dictadura" del medio en donde viven. Tal como explica Castellanos a propósito de la narrativa de Víctor Català -cuyos Drames rurals (1902) publicados en Joventut a lo largo de 1902 sin duda Sabartés conocía, ya que su aparición coincide con la de sus propias narraciones en la misma revista-en un fragmento que encaja perfectamente con el tema de fondo de Don Julián y de Son Excellence, esta narrativa "habla de la realidad cotidiana y no confía nunca en elementos abstractos, ni ideológicos, ni obviamente, al naturalismo positivista, el destino de los personajes. La hostilidad general del medio es precisada: la víctima humana no lo es únicamente porque la sociedad, el medio, la herencia o la educación (términos que en última instancia responden a abstracciones) le conviertan en víctima, sino porque es un ser humano y el ser humano solamente es humano si quiere serlo, cuando hace de su sensibilidad, de su emotividad, un punto de partida para crearse, para superarse a sí mismo. Pero las condiciones de miseria en que vive, la lucha por la vida o el mismo destino que le domina y le empuja, no le permite dar este paso y le mantienen en un estadio primario, animalizado, en el cual, falto de ideales y de sentimientos, se convierte en víctima y verdugo al mismo tiempo; y cada individuo se inviste, en su inconciencia, en irresponsable ejecutor de la hostilidad general" (Castellanos 607).

Revista Iberoamericana, Vol. LXXXI, Núm. 250, Enero-Marzo 2015, 31-52 ISSN 0034-9631 (Impreso)

ISSN 2154-4794 (Electrónico) 
Don Geno pasará dos días y dos noches en casa del cuñado. El primero de ellos, sale por la mañana y recorre las calles de su ciudad natal en búsqueda de noticias, aunque más que noticias encuentra indicios de ellas a través de los rumores y los chismes que corren sobre la desaparición de Don Julián. El cuñado, pues, visita a sus amigos de juventud reunidos en el casino, se acerca a un céntrico comercio regentado por cuatro hermanos catalanes con quienes come en una fonda frecuentada también por emigrantes que han establecido sus comercios en la capital, visita infructuosamente al padre Francisco y se aleja hasta los aledaños de la estación, donde habita una especie de trapero que acostumbra a tener información privilegiada sobre lo que acontece en los intestinos de la ciudad. Ya de regreso, sin haber conseguido sacar nada en claro y con la sensación de impotencia de quien comprueba la eficacia de un engranaje basado en la corrupción y en el miedo, Don Geno se encuentra por la calle a un viejo amigo abogado que le invita a su casa y le explica, tras cerciorarse de que nadie puede escucharles -vecinos, transeúntes, sirvientes-, los mecanismos del control social de un régimen presidido por "el Patrón", "Su Excelencia” o "el Señor Presidente", que en la novela va a permanecer -al igual que en la novela homónima de Miguel Ángel Asturias- en un lugar difuso, invisible y sin embargo omnipresente y todopoderoso. La sensación de claustrofobia que la novela produce en el lector se intensifica a partir de este instante con el análisis pormenorizado del miedo que experimenta Don Geno. De vuelta a casa, se arrepiente de haber aceptado la invitación del amigo para cenar al día siguiente. Don Geno ha necesitado permanecer sólo un día y una noche en la ciudad para convertirse en presa del miedo, en un individuo sin capacidad de reacción, paralizado, alienado.

Con el último recorrido del personaje por la ciudad se puede decir que termina la novela. Por de pronto, a diferencia del día anterior, Don Geno no sale de casa del cuñado hasta la hora de su cita, a la que acude por pura cortesía y con los cinco sentidos puestos en el terror psicológico de la vuelta, ya de noche, a través de una ciudad expresionista, con contrastes de aguafuerte, llena de peligros donde las paredes oyen, las ventanas sin luz ocultan miradas escrutadoras y las esquinas protegen a probables agresores o secuestradores, mientras manadas de siniestros y quizá sólo presentidos zopilotes se mantienen al acecho. Don Geno llegará psicológicamente destrozado a la casa, donde le espera Cristina y donde todo parece haber vuelto a la normalidad después de que la familia ha asumido la desgracia y se dispone a continuar su vida doméstica con sólo unos pocos cambios en la distribución del espacio a partir del mismo instante en que se confirme lo que ya es una evidencia, la muerte del desaparecido. Cuando regresa de su simbólico viaje iniciático por la ciudad, Don Geno es ya un personaje derrotado, paralizado, envejecido, avergonzado de su propio miedo, impotente, fracasado. Y mientras se debate interiormente entre el deber de quedarse en la ciudad respaldando a los suyos y el inmediato regreso a la pretendida tranquilidad del campo, llega la noticia de la aparición del cadáver de Don Julián y la evidencia de su muerte, considerada oficialmente como un suicidio. 


\section{La novela del “Benemérito de la Patria”, Manuel Estrada Cabrera}

La segunda novela del dictador de Jaume Sabartés, firmada en París el 10 de junio de 1945 con el título de El Benemérito, ${ }^{15}$ apareció publicada en 1949 -en traducción francesa de Geneviève Laporte- con el título de Son Excellence. "Su Excelencia" es uno de los nombres, junto con "el Patrón" o "el Benemérito de la Patria", con que se conoce en la novela al protagonista, el Licenciado Prudencio Marañas, sucesor del Jefe de Estado asesinado el mismo día en que Olegario, un joven emigrante catalán, llega a su destino, una ciudad de nuevo sin nombre de Centroamérica. Más ambicioso, estructuralmente hablando, que Don Julián, el relato yuxtapone las historias de dos personajes que nunca llegan a encontrarse por bien que la existencia del uno implique y explique la existencia del otro en una circunstancia histórica y en un tiempo y un lugar muy delimitados - unos pocos meses en un país de dimensiones pequeñas- que reproduce, tal como Arturo Uslar describe en relación a El Señor Presidente, "un ambiente de círculo infernal" en cuyo centro se encuentra el tirano. Si en la novela de Asturias, sin embargo, el tirano es visto desde fuera como una figura "enteca y malhumorada" y el narrador nunca llega a asomarse a su interioridad o a tratar de explicarlo" porque "está allí y se mantiene allí por una especie de designio fatal" (Uslar 513), en Son Excellence el narrador omnisciente -desdoblado en cronista- insiste en focalizar la figura del dictador, en procurar conocer, además de sus maquinaciones y las maniobras de los que le rodean, sus motivos personales y la complejidad de la maquinaria social que propicia su misma existencia. En este sentido, la novela de Jaume Sabartés, cuyo dictador responde, al igual que El Señor Presidente, al modelo histórico de Manuel Estrada Cabrera - un civil o militar que logra "por ardides o por fuerza asaltar el poder y mantenerse en él, sin ninguna forma de legalidad posible o alegable" (Uslar 514)-, pretende denunciar una tragedia colectiva a través del análisis de la realidad política y social, es decir, en términos históricos.

Después de un largo viaje transatlántico más o menos tedioso y de un desembarco complicado que previene sobre las dificultades que se van a encontrar en su nuevo destino, el joven y taciturno Olegario, junto con dos parejas de catalanes dispuestos a empezar una nueva vida en un país innominado de la América tropical, llegan a la ciudad donde

\footnotetext{
15 La copia mecanografiada que se conserva en el "Fons Sabartés" del Museu Picasso de Barcelona de la versión en español de Son Excellence, El Benemérito, está encuadernada en dos mitades $\left(1^{\mathrm{a}} \operatorname{mitad} / 2^{\mathrm{a}}\right.$ mitad El Benemérito sigue de la pág. 176 a la pág. 358) religadas manualmente con un cordel y cubiertas de color azul desteñido. El título de la novela, El Benemérito, está escrito en tinta azul/violeta. En la segunda página del primer volumen puede leerse en el ángulo superior derecho de la página la dirección de Sabartés en París: 88 rue de la Convention Paris XV. Ocupan el espacio central el nombre del autor, J. Sabartés, el título de la novela, El Benemérito, y el lugar y fecha donde se finalizó la obra: París 10 / V. 1945. Esta fecha no coincide, sin embargo, con la que aparece en la página 358, 10 de junio de 1945.
}

Revista Iberoamericana, Vol. LXXXI, Núm. 250, Enero-Marzo 2015, $31-52$ ISSN 0034-9631 (Impreso) ISSN 2154-4794 (Electrónico) 
vive el tío del primero, un catalán emigrado hace años, Joaquín Mascaró, que regenta un pequeño hotel cerca del centro llamado Hotel de Ambos Mundos, en medio del colapso que supone el reciente asesinato por parte de un extranjero del primer mandatario del país. A partir de este instante, la novela se despliega en dos tramas paralelas. Por una parte, la que, a través del hilo conductor del personaje de Olegario, describe la sociedad centroamericana desde los ojos extrañados del outsidery resigue el proceso de aclimatación y, por lo tanto, de aceptación de sus reglas, del recién llegado. Por otra parte, la trama protagonizada por el sucesor del presidente asesinado, un personaje gris que nadie -ni siquiera los que inconscientemente lo propiciaron- entiende cómo ha podido llegar al poder pero que en seguida demuestra tener claras intenciones de perdurar en él como lo demuestra el inmediato golpe de Estado que perpetra tanto como la consiguiente implantación de un régimen político, militar y administrativo fundamentado en la eficaz combinación de terror, inseguridad y corrupción. Las dos tramas se interrelacionan a través de un tercer personaje, capital en el desarrollo de la mínima acción que sirve de motor al relato novelístico y que constituye, según mi parecer, la principal aportación al subgénero de la novela del dictador donde cabe situar las dos novelas de Jaume Sabartés. Se trata de Domingo Turó, barbero del Licenciado Prudencio Marañas antes y después de convertirse éste en "Su Excelencia", el apodo que más veces aparece en el texto y que explica el título de la versión francesa -y única publicada- de la novela.

Al inicio de El recurso del método (1974), de Alejo Carpentier, uno de los mayores hitos de la novela del dictador, es el tándem entre el barbero y el sastre del Primer Magistrado quien arropa al protagonista de la novela, un dictador irónicamente cansado, ausente del país al que controla con mano férrea pensando en su pronta jubilación en la ciudad donde se refugia, París, cuna de la civilización europea y el gran referente de la intelectualidad hispanoamericana durante la primera mitad del siglo xx (Colombi s. p.), además de la ciudad donde tanto Asturias como Sabartés escribieron sus novelas. Barbero y sastre forman parte del cortejo que, desde su segundo hasta la "mayorala" que se ocupa de la hamaca del dictador, le acompaña en todo momento y funciona como un muro protector en la novela. En Son Excellence, Sabartés convierte al barbero en un personaje con vida propia, limítrofe entre "ambos mundos" -el nombre del hotel del tío de Olegario en cuyos "bajos" tiene Domingo su establecimiento, "La Francesa", y donde come y cena a diario-, entre el círculo cerrado del gobernador y la sociedad gobernada, y entre el "allá" y el "acá", Europa versus América, una de las constantes temáticas de la novela del dictador.

Al igual que Joaquín y Olegario, Domingo es un emigrante español, catalán -entre ellos, estos personajes se interpelan mediante sus respectivos diminutivos en catalán, Mingo y Quim-, solitario y discreto a la par que trabajador empedernido, desconfiado y taciturno como su principal cliente, que va a tener acceso a la intimidad del Benemérito gracias a estas cualidades compartidas. Desde los ojos del barbero, la disección de la

Revista Iberoamericana, Vol. LXXXI, Núm. 250, Enero-Marzo 2015, 31-52 ISSN 0034-9631 (Impreso)

ISSN 2154-4794 (Electrónico) 
personalidad del protagonista resulta casi tan importante como la descripción del engranaje de una maquinaria estatal diseñada no sólo para vetar el acceso de la población a la cosa pública, sino para que, tal como explica el narrador desde su condición de cronista, la población llegue a aceptar algo tan paralizante, en relación con la "Carta Fundamental" del país, como que "la "letra" y la "realidad" son cosas distintas:

La astucia le había enseñado a temer por igual la Ley y el Palo. Había tenido demasiadas oportunidades para comprobarlo: la ambición de algunos, apoyada en la ilusión de un grupo, que creyó en la posibilidad de contar con fuerzas para apoyar "derechos" mencionados en el texto de la Constitución, y los fracasos inmediatos, observados en uno mismo o en cuerpo ajeno, no tardaron en enseñar al pueblo que valía más ser prudente (76-77).

Prudencia: he aquí uno de los valores distintivos de la pequeña burguesía comercial catalana que se convirtió, con el nombre de "seny" en uno de los pilares maestros del discurso ideológico del catalanismo conservador a comienzos del siglo xx y que uno de los artistas y escritores modernistas por excelencia, Santiago Rusiñol, convertiría a través de su novela L'auca del senyor Esteve (1907) en el arquetipo de la mentalidad pequeñoburguesa. Una de las principales consecuencias de la prudencia es el posibilismo político que caracteriza, en el contexto de Son Excellence, a un segmento de la sociedad hispanoamericana que Sabartés conoce de primera mano y cuya peculiar situación, equidistante del mundo de los indígenas como de la oligarquía criolla, no duda en utilizar como punto de vista desde el cual abordar la figura del dictador y el tema de la tiranía sin caer en maniqueísmos que el autor intenta a todas luces evitar. Quizás sea ésta la principal causa de la incomodidad que crea en el lector la lectura de Son Excellence y que explicaría el comentario de uno de los pocos críticos de la novela, Luis Luján Muñoz, biógrafo del período guatemalteco de Sabartés, cuando afirma que "es sobre todo en sus dos novelas Don Julián y Son Excellence en donde se pueden apreciar esta ironía, ese sarcasmo y un profundo desencanto de la vida" (Luján 27).

En este sentido, ni Domingo ni Joaquín son capaces de valorar la situación política del país donde viven más allá de las pérdidas o los beneficios de sus respectivos negocios. Ambos procurarán favorecer al máximo al joven Olegario, llegado en mala hora, como repiten una y otra vez, y por ello le inculcarán la prudencia como forma de vida en un medio donde sobrevive quien logra pasar desapercibido o quien consigue entender y adaptarse a las reglas del juego. Olegario, descrito desde el primer momento como un joven solitario, taciturno y abúlico, llega a su destino en un "lanchón" llamado Libertad:

Exactamente, Libertad. Cuando buscaba el nombre no venía y ahora que no lo busco se presenta... "Libertad".

Revista Iberoamericana, Vol. LXXXI, Núm. 250, Enero-Marzo 2015, 31-52 ISSN 0034-9631 (Impreso)

ISSN 2154-4794 (Electrónico) 
Nombre de buen augurio. Palabra mágica. La expresión más adecuada para ilusionar al pasajero que se refugia en un país (28).

Al final de la novela, irónicamente, de nuevo esta palabra aparecerá en el pensamiento del muchacho, pero será después de haber asistido a los fastos por la proclamación del Licenciado Prudencio Marañas como presidente electo de la República. Y enlazará, también irónicamente, con el mismo nombre del dictador:

Hay que dejar a su Excelencia y a su secretario particular enfrascados en la difícil tarea de modelar la moral de toda la nación. Su norma era el trabajo y el ideal de gobernar sin disturbios, de fabricar una paz casi perfecta, de construir un sistema perdurable. Los dos eran prudentes y obraban con cautela: su paciencia era incalculable, ninguna dificultad les desmayaba. Prolongando la estancia en el poder estaban convencidos de poder hacer obra perfecta: necesitaban durar, porque confiaban en ellos y en el tiempo... Dejémosles pues, entregados a su labor tan absorbente, a tan laudable propósito (229).

Sólo unos pocos meses han bastado para integrar a Olegario, quien, después de considerar y rechazar los atractivos sexuales de la Tote-la muchacha indígena que sirve en el hotel cuyo "exotismo" le atrae y cuyos pies descalzos le repelen- o la amistad peligrosa del joven Gustavo, espíritu libre, contrario al régimen, representante de unas de las familias más antiguas del país que sin embargo vive encerrada entre las paredes de su mansión evitando el contacto con el exterior, decide acercarse a los también catalanes dueños de El Túnel, una tienda de ultramarinos con una hija casadera, la Nena, cuyo nombre es lo único que conserva la familia de "allá", habiendo aceptado, al legalizar el establecimiento, que su nombre catalán "Figueres" pasara de un plumazo por gracia y autoridad del funcionario de turno al español "Higueras" renunciando a su principal seña de identidad. Antes de cortejar a la Nena, simbólicamente, Olegario va a tomar su primera dosis de alcohol (353).

La novela termina con una irónica referencia al Himno de Riego por parte de un Olegario que, antes de meterse en la cama después de su primera inmersión en la multitud reunida para festejar la fraudulenta legitimación de Su Excelencia en el poder, decide integrarse en ella:

Olegario cerró la puerta cautelosamente cuidando de no hacer ruido, se guardó el llavín; puso el sombrero en la percha del despacho y tomó la escalera, camino de su cuarto, pensando en hacer otra vida.

-Mañana iré a ver a los vecinos. Por qué no he de ir!... Hay algo que aprender con esa gente. Hasta aquí he vivido en el limbo... "Ni tiranos, ni cadenas, ni azotes..." De dónde viene eso? Ah! Ya sé... "Libertad!... Libertad!... Libertad!" (358)

Revista Iberoamericana, Vol. LXXXI, Núm. 250, Enero-Marzo 2015, 31-52 ISSN 0034-9631 (Impreso) 
Multitud, masa, pueblo: todos estos nombres sirven a Sabartés para referirse a la sociedad que, como la naturaleza salvaje del trópico, acaba engullendo al individuo. Porque de la identidad del individuo - exiliado, emigrante, desplazado- es de lo que habla también Son Excellence, partiendo de la experiencia autobiográfica del autor. Olegario va a perder su identidad en el totum revolutum de una sociedad compleja, históricamente maltratada, escarmentada, de cuyo mismo seno surge el tirano, víctima y verdugo al mismo tiempo, igual que son víctimas y verdugos todos y cada uno de los miembros que constituyen su abigarrada mescolanza. Las diferentes clases sociales, perfectamente delimitadas e impermeables, se sustentan sin embargo sobre la explotación del indígena -que ocupa siempre el último escalafón de la sociedad y aparece representado como sirviente, mozo, peón o soldado- y viven condicionadas por el agiotaje, la especulación monetaria, representado en la novela a través de "Casa Schamlos" - en alemán "Sinvergüenza"- frecuentada por el Ministro de Finanzas de los diferentes gobiernos del país de Son Excellence.

Este país donde "la fuerza de la autoridad que se creaba residía en el delito" (228), donde "la ley significaba poca cosa para la masa" (196), donde no existe familia sin algún miembro preso, desaparecido o asesinado (331-332), donde la prensa es corrupta (287), donde lo mismo da que el poder se encuentre en manos de un civil que de un militar (190), donde "para gobernar en paz ningún recurso podía parecer tan fácil [al gobernante] que crear la miseria y sembrar la desconfianza en torno suyo" (203) y donde nadie, ni siquiera la mano derecha del Presidente, está a salvo de sus arbitrariedades (342), se convierte en el principal protagonista de Son Excellence y de Don Julián de Jaume Sabartés.

Son numerosos y significativos, a la par que reconocidos (Laporte 88-94; Grajeda s. p.; Luján 27), los paralelismos que existen entre las dos novelas guatemaltecas de Sabartés y la novela de Miguel Ángel Asturias El señor presidente: el ambiente de la dictadura de Manuel Estrada Cabrera, las peculiaridades de la personalidad del dictador, el atentado como motor de la acción, un golpe de estado más o menos encubierto, la fuga y exilio de un general, el protagonismo de la mano derecha o del favorito del Benemérito de la patria, la corrupción como método de control social, la violencia política, el miedo, la delación, la insolidaridad, la desconfianza, la división social, la invisibilidad del indígena, la agresividad de una naturaleza furiente. Publicada en 1946 en México, D. F. por la editorial Costa-Amic después de una redacción escalonada que empieza en la década de los veinte y culmina en 1933, la novela de Asturias consigue integrar las historias individuales de los personajes aprisionados por los hilos que mueve sin piedad el dictador - puros títeres de un grotesco teatro de marionetas- en un escenario esperpéntico que reproduce la tiranía como sistema político de unas sociedades atrapadas en la maraña -Prudencio Marañas es precisamente el nombre de "Su Excelencia" protagonista de la novela de Jaume Sabartés- que surge de las mismas entrañas de la

Revista Iberoamericana, Vol. LXXXI, Núm. 250, Enero-Marzo 2015, $31-52$ ISSN 0034-9631 (Impreso)

ISSN 2154-4794 (Electrónico) 
naturaleza con la que el individuo entabla una continuada, cruenta y atávica lucha de la cual nunca consigue salir vencedor.

En El Señor Presidente, Asturias consigue construir esta maraña a partir de las voces de hombres y mujeres, niños y viejos, ricos y pobres, ebrios y sobrios, ángeles y demonios, prostitutas y titiriteros, animales y plantas, calles y casas, piedras y pantanos, vivos y muertos, que corren, gritan, lloran, se desgarran, nacen, mueren, se metamorfosean en medio de una especie de maleza que les mantiene agarrados, como insectos que se mueven inútilmente en la tela de araña. Las múltiples voces de los personajes de Asturias conforman el estilo de una novela que la crítica ha considerado un punto de referencia en la literatura de América Latina, una de las obras clave del subgénero literario de la novela del dictador, y a su autor como uno de los primeros en utilizar la técnica conocida como "realismo mágico" a partir de las influencias del surrealismo que acertó a adaptar a la novela en pleno proceso de renovación del género en la época de entreguerras (Martin xxv-xxvii).

Por su parte, Jaume Sabartés coincide con Asturias en la importancia que otorga a la naturaleza, hasta convertirla en un elemento simbólico que contribuye a trascender la tesitura realista de ambos relatos y a otorgarles un significado universal. En Don Julián, por ejemplo, las primeras frases de la novela se refieren al clima de una tierra donde "el sol está como en su casa" (1), la vida de los habitantes de la casa del desaparecido gira alrededor de las lluvias que cada tarde penetran en los patios, mucho más benefactoras sin embargo que todo lo demás que pueda llegar del exterior, especialmente las personas (93-95) y, en uno de los pocos momentos en que el narrador focaliza el personaje de Don Julián a través de un flash-back motivado por la necesidad de Cristina y Don Geno de recordar los últimos movimientos de la víctima, la selva que separa físicamente y simbólicamente el "acá" del "allá" merece una de las más extensas descripciones de la novela.

Don Julián está a punto de emprender un viaje que le llevará a Europa y del que sus allegados consideran que no hubiera tenido que volver. El personaje está aterrido porque sabe que puede ser víctima de cualquier encerrona. Está viajando en el tren que le conduce al barco y la máquina se avería. Es su compañero de viaje quién explica el miedo de Don Julián, el "padre Lolo", de cuyos ojos surge la descripción del sonido de la selva:

Una vez apagado el último resuello de la locomotora, los oídos fatigados percibieron el zumbido de los moscardones que revoloteaban en torno del vagón. A eso se atravesaba la agudísima nota, torturante y cruel, del silbido de los mosquitos, sin cesar ni un instante, clavando el alfiler de su chillido en las sienes y embotando los sentidos. Los demás ruidos de la selva prestaban su concurso haciendo coro a los rumores que salían de todas partes: entre los troncos de los árboles, de dentro de las cortezas y aún tal vez de debajo, y de las ramas, de entre las matas resecas, imitando toda clase de gemidos y

Revista Iberoamericana, Vol. LXXXI, Núm. 250, Enero-Marzo 2015, 31-52 ISSN 0034-9631 (Impreso) 
de voces; simulando un chasquido repetido por doquier, hasta el infinito, unos, y otros, como si tuvieran el empeño de cortar los miles y millones de chillidos esparcidos por el aire, más o menos agudos, mezclándose con el ritmo perenne de un número infinito de chicharras que parecían untar la masa del aire envuelto en tanto grito, con su tijereteo. Por si eso no fuera suficiente, de las entrañas mismas de la tierra, o quién sabe dónde, subía un rumor como de algo que bulle: algo invisible que se hace sentir a través del susurro pertinaz, constante, infatigable [...].

El vaho que subía del suelo parecía la vaporización de un sudor producido por un esfuerzo incesante, por una agitación sin término. El sol, echado encima de este amontonamiento, apenas alcanzaba a taladrarlo con sus rayos candentes, y la tierra se abría en grietas para que el calor pudiera penetrarla, hacerla herir y jadear y sacarle esa baba y ese clamor estridente que uno no acierta a explicar, dejando una impresión de obscenidad repelente. ${ }^{16}$

La misma barrera que el protagonista de Don Julián debe traspasar para recuperar pasajeramente la tranquilidad, tiene que franquearla el joven emigrante Olegario tras su viaje transoceánico. Es una frontera simbólica, representada a través de la descripción del calor, la que tiene que traspasar el personaje como un rito de entrada al mundo asfixiante de Son Excellence:

En ayunas por primera vez en toda su vida, desalentado, sudoroso y aburrido, consumiéndose bajo los ardores de un sol despiadado, había perdido las ganas de pensar. Una tierra que le recibía de tal modo no le parecía adecuada para fomentar esperanzas. El paisaje era tan desolado, tan despejado el cielo y tan azul, que no ofrecía ningún halago a la codicia de los ojos. [...]

Ya no pensaba en el buque que había dejado atrás, ni en su país, ni en lo que de sí había quedado en el curso de la travesía, porque apenas tenía conciencia de quién era (26-28).

La “América furiente", que resuena en la violencia de la luz del país y se metaforiza en los pies descalzos de "la Tote" (141)-repetidamente evocados por Olegario- y de los soldados de a pie (236), determina según el propio narrador la dureza de la "crónica" (76-77) del fracaso individual y colectivo en el contexto de la tiranía.

\section{La fortuna de Don JULIÁN y SON EXCELLENCE}

A diferencia de El Señor Presidente, que obtuvo una inmediata y prácticamente unánime recepción como novela que abría nuevos cauces a la narrativa hispanoamericana (Liano 613-629) y que fue leída -no obstante el interés del autor de desmarcarse de la literatura engagée que se afianzó en el contexto de la segunda postguerra mundial-por

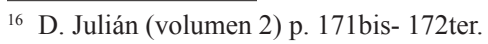

Revista Iberoamericana, Vol. LXXXI, Núm. 250, Enero-Marzo 2015, 31-52 
grupos de izquierdas como crítica a la tiranía en general y a las dictaduras latinoamericanas en particular, ${ }^{17}$ ni Don Julián ni Son Excellence consiguieron traspasar el limitado círculo de lectores vinculados ideológicamente al Parti Communiste Français, bajo cuyo amplio paraguas fueron editadas las dos novelas en La Bibliothèque Française que también editó la revista Europe (1923-1939), reanudada por Louis Aragon y dirigida por Pierre Abraham, a partir de $1946 .{ }^{18}$

Jean Cassou, uno de los nombres relevantes del Mouvement de la Paix al que Picasso se adhirió personalmente, colaborador de Europe desde su aparición y director desde 1936 hasta que fue suspendida tras el Pacto germano soviético Ribbentrop-Molótov en agosto de 1939 siguiendo la vía comunista en la lucha antifascista, confesaba en un artículo publicado póstumamente la poca importancia que las letras francesas habían concedido a la literatura hispanoamericana hasta la eclosión de la moderna narrativa de los años sesenta. Sus palabras se referían a El Señor Presidente (Cassou 730-742). ¿Qué no debería pasar entonces con las novelas un escritor catalán que escribe en español dos novelas del dictador publicadas en francés en una editorial de la órbita comunista inmediatamente después del desenlace de la Segunda Guerra Mundial y que, además, se llama Sabartés y es conocido como la sombra de Picasso?

\section{FUENTES CITADAS}

Arévalo Martínez, Rafael. El hombre que parecía un Caballo y otros cuentos. Edición crítica. Coord. Dante Liano. ALLCAXX: Editorial Universidad de Costa Rica, 1997. Asturias, Miguel Ángel. El Señor Presidente. Edición crítica. Coord. Gerald Martin. ALLCA XX/ Université: Paris X, 2000.

Basso, Eleonora, Carlos Demasi, Norah Giraldi Dei Cas y Fatiha Idmhand. "Trayectoria de José Mora Guarnido. Espejo de un intelectual entre España y América (19231939)". Viajeros, diplomáticos y exiliados. Escritores hispanoamericanos en España (1914-1939). 2 vol. Carmen de Mora, Alfonso García Morales, eds. Berna: Peter Lang, 2012.

Bellini, Giuseppe. El tema de la dictadura en la narrativa del mundo hispánico (Siglo XX). Roma: Bulzoni Editore, 2000.

17 Véase Taracena Arriola, Arturo. "Miguel Ángel Asturias y la búsqueda del "alma nacional” guatemalteca. Itinerario político, 1920-1933”. En Segalà, Amos (ed.). Migel Ángel Asturias, París 1924-1933 670-708. Agradezco al Doctor Taracena Arriola sus interesantes comentarios sobre el pecyliar rol intelectual que representó Jaume Sabartés en la Guatemala del primer cuarto del siglo Xx.

18 Véase Bouju, Marie-Cécile. La production des maisons d'édition du P.C.F. (1921-1956). Mémoire d'Étude, 2 volumes. École Nationale Supérieure des sciences de l'Information et des Bibliothèques, 1999.

Revista Iberoamericana, Vol. LXXXI, Núm. 250, Enero-Marzo 2015, 31-52 ISSN 0034-9631 (Impreso)

ISSN 2154-4794 (Electrónico) 
Calviño Iglesias, Julio. La novela del dictador en Hispanoamérica. Madrid: Ediciones de Cultura Hispánica. Instituto de Cooperación Iberoamericana, 1985.

Campillo, María. "Breve informe sobre el exilioliterario catalán”. EnAznar Soler, Manuel ed., Las literaturas exiliadas en 1939. Biblioteca Virtual Universal, 2003, 37-43.

Cassou, Jean. "Asturias en París: Un descubrimiento recíproco”. En Segala, Amos ed., Miguel Ángel Asturias, París 1924-1933. Periodismo y creación literaria, 730-742.

Castellanos, Jordi. "La novel·la modernista"; "Víctor Català". Història de la Literatura Catalana. Part Moderna, VIII. Joaquim Molas, dir. Barcelona:Ariel, 1986. 481-623.

Colombi, Beatriz. "Una ciudad letrada extraterritorial: escritores hispanoamericanos en París en el fin-de-siglo". Una ciudad letrada extraterritorial. Abril 2011. Web. 14 de noviembre de 2014.

Viaje intelectual. Migraciones y desplazamientos en América Latina 1880-1915. Rosario: Beatriz Viterbo, 2004.

Daix, Pierre. Les après-guerres de Picasso (1945-1955) et sa rupture avec Aragon. Neuchâtel: Éditions Ides et Calendes, 2006.

Díaz Rozzotto, Jaime. “Origines et originalité de la littérature guatémaltèque”. J. Garavito, trad. Europe 46/473 (sept, 1968): 27-46.

Dorfman, Ariel. Imaginación y violencia en América. Barcelona: Anagrama, $1972\left(2^{\mathrm{a}}\right)$.

Flores Espinoza, Juan Carlos. El dictador latinoamericano y su víctima: yuxtaposición analítica de las figuras literarias en América Latina (siglo XX). Dissertation Zur Erlangung des Doktorgrades an der Pholologisch-Historischen Fakultät der Universität Augsburg, 2006.

Gallego Cuiñas, Ana. Trujillo: El fantasma y sus escritores (Análisis y sistematización de la novela del trujillato). Tesis Doctoral. Universidad de Granada, Departamento de Literatura Española, 2005.

García, Juan Carlos. El Dictador en la novela hispanoamericana. University of Toronto: Bibliothèque Nationale du Canada, 1999.

Grajeda Mena, Guillermo. "Picasso y Sabartés". Plástica guatemalteca en homenaje a Picasso. Guatemala: Organización Paiz, 1981. s. p.

Laporte, Geneviève. "Si tard le soir...” Pablo Picasso. París: Librairie Plon, 1973.

Léal, Brigitte. "Picasso et Sabartés: « l'image parfaite de la solitude à deux »". Jaime Sabartés, Picasso. Portraits et souvenirs. Paris: L'École des Loisirs, 1996. 283-295. Liano, Dante. "Recepción de la obra de Miguel Ángel Asturias en Guatemala". En Asturias, Miguel Ángel, El Señor Presidente 613-619.

Luján Muñoz, Luis. “Jaime Sabartés: Intelectual español en Gualtemala”. Guatemala: Impr. Hispania, 1966. 25-27.

Luján Muñoz, Luis. Jaime Sabartés en Guatemala: 1904-27. Guatemala, C.A.:Dirección General de Bellas Artes, 1981.

Luján Muñoz, Luis. “Carlos Mérida, Sabartés y Carlos Valentí”. Anales del Instituto de Investigaciones Estéticas 54 (Universidad Autónoma de México, 1984): 195-218.

Revista Iberoamericana, Vol. LXXXI, Núm. 250, Enero-Marzo 2015, 31-52 ISSN 0034-9631 (Impreso)

ISSN 2154-4794 (Electrónico) 
Marfany, Joan-Lluís. Aspectes del Modernisme. Barcelona: Curial, 1975.

Martin, Gerald. "Introducción del coordinador". En Asturias, Miguel Ángel, El Señor Presidente xxv-xxxviii.

McCully, Marilyn. Devorar París. Picasso 1900-1907. Amsterdam: Van Gogh Museum; Barcelona: Museu Picasso Brusselles: Mercatorfonds, 2011.

Mejía Ruiz, Carmen. La figura del dictador en la novela moderna y contemporánea: narrativa hispanoamericana. Madrid: Universidad Complutense, 1987.

Pacheco, Carlos. Narrativa de la dictadura y crítica literaria. Caracas: Fundación de Estudios Latinoamericanos Rómulo Gallegos, 1987.

Rodríguez Pérez, Osvaldo. "Dos modelos de la novela de la dictadura hispanoamericana: Tirano Banderas de Valle Inclán y El Señor Presidente de M. A. Asturias". Alpha 11 (1995): 41-50.

Sabartés, Jaime. Picasso. Retratos y recuerdos. Madrid: Afrodisio Aguado, 1953. Picasso. Documents iconographiques. Genève: Pierre Cailler Éditeur, 1954.

Segala, Amos (ed.). Miguel Ángel Asturias, París 1924-1933. Periodismo y creación literaria. Madrid: Archivos, 1988.

Subercaseaux, Bernardo. "Tirano Banderas en la narrativa hispanoamericana (La novela del dictador, 1926-1976)”. Hispamérica 14 (1976): 45-62.

Taracena Arriola, Arturo. "Miguel Ángel Asturias y la búsqueda del "alma nacional" guatemalteca. Itinerario político, 1920-1933". En Segala, Amos ed., Migel Ángel Asturias, París 1924-1933 670-708.

Uslar Pietri, Arturo. "Yo asistí al nacimiento de El Señor Presidente". En Asturias, Miguel Ángel, El Señor Presidente 509-514.

Zuluaga, Conrado. Novelas del dictador. Dictadores de novela. Bogotá: Carlos Valencia Editores, 1977. 